\title{
Incentivo e Promoção da Alimentação Complementar Saudável na Consulta de Enfermagem à Criança
}

\author{
Priscilla Shirley Siniak dos Anjos Modes, ${ }^{1}$ Maria Aparecida Munhoz Gaíva, ${ }^{2}$ \\ Caroline Aparecida Coutinho Monteschio²
}

\begin{abstract}
RESUMO
Objetivo: Analisar a prática assistencial do enfermeiro, voltada ao incentivo e promoção da alimentação saudável na consulta de enfermagem à criança menor de dois anos. Método: Pesquisa descritiva exploratória de abordagem qualitativa, realizada em quatro Unidades de Saúde da Família (USF), do município de Cuiabá-MT. Utilizou-se a observação participante em 9 consultas de enfermagem à criança entre 6 e 24 meses nas unidades selecionadas para o estudo. Resultados: Identificou-se a categoria temática Promoção de hábitos alimentares saudáveis na consulta de enfermagem à criança. Durante as consultas, os enfermeiros incentivaram e promoveram a alimentação complementar, investigando práticas alimentares e orientando as mães. Por outro lado, ações específicas, como orientações das peculiaridades da alimentação infantil e influência dos aspectos culturais, não foram contempladas. Conclusão: Investimentos na capacitação do enfermeiro são fundamentais para um atendimento integral voltado à alimentação.
\end{abstract}

Palavras-chave: Alimentação. Nutrição da criança. Assistência alimentar. Enfermagem no consultório. Dieta saudável.

INCENTIVE AND PROMOTION OF HEALTHY SUPPLEMENTARY FOOD IN THE NURSING CONSULTATION OF THE CHILD ABSTRACT

Objective: To analyze the nursing care practice, aimed at encouraging and promoting healthy eating in the nursing visit to children under two years of age. Method: Exploratory descriptive research with a qualitative approach, carried out in four Family Health Units (USF), in the city of Cuiabá-MT. The participant observation was used in nine nursing consultations to the child between six and 24 months, in the units selected for the study. Results: It was identified the thematic category Promotion of healthy eating habits in the nursing consultation to the child. During the consultations, nurses encouraged and promoted complementary feeding, investigating feeding practices and mentoring mothers. On the other hand, specific actions like orientations about the peculiarities of the infantile feeding and influence of the cultural aspects were not contemplated. Conclusion: Investments in the training of nurses are fundamental for an integral care focused on nutrition.

Keywords: Feeding. Child nutrition. Food assistance. Office nursing. Healthy diet.

RECEBIDO EM: 11/3/2020

MODIFICAÇÕES SOLICITADAS EM: 2/7/2020

ACEITO EM: 12/8/2020

\footnotetext{
Autora correspondente. Universidade Federal de Mato Grosso, Campus Sinop. Sinop/MT, Brasil. Rua Berna, 420, Residencial Bella Suíça, Sinop/MT. CEP 78556-594. http://lattes.cnpq.br/8914619479763431. https://orcid.org/0000-0003-2039-4505. priscilladosanjos@yahoo.com.br

2 Universidade Federal de Mato Grosso. Cuiabá/MT, Brasil.
} 


\section{INTRODUÇÃO}

Entidades mundiais (WHO, 2009; WHO, 2018a), para além do Ministério da Saúde (MS) (BRASIL, 2015a), da Federação Brasileira das Associações de Ginecologia e Obstetrícia (FEBRASGO, 2018) e da Sociedade Brasileira de Pediatria (SBP, 2012, 2018), recomendam o aleitamento materno por dois anos ou mais, sendo de forma exclusiva nos primeiros seis meses de vida. Ao completar seis meses, é recomendada a introdução de alimentos complementares, uma vez que, antes desse período, o leite materno é capaz de suprir todas as necessidades nutricionais do bebê (BRASIL, 2015b).

Entende-se por alimentação complementar o conjunto de alimentos, além do leite materno, que é oferecido durante o período em que a criança continuará a ser amamentada ao seio, ainda que sem exclusividade, tendo seu início a partir dos seis meses de vida, com dietas apropriadas em quantidade e qualidade e atendendo às recomendações quanto aos macros e micronutrientes (SBP, 2012).

E é a partir dos 6 meses de idade que a necessidade de energia e nutrientes de uma criança começa a exceder para além do que é fornecido exclusivamente pelo leite materno, havendo a necessidade da introdução de alimentos complementares para atender a essas necessidades. Nos casos em que os alimentos complementares não forem introduzidos no momento oportuno em que a criança se encontra fisiologicamente preparada, ou se forem dados de forma inadequada, o seu crescimento poderá ser prejudicado (WHO, 2018b) e futuramente ocasionar excesso de peso (PLUYMEN et al., 2018).

A idade correta para iniciar a introdução alimentar é importante por causa da maturidade neurofisiológica do bebê. Além disso, é preciso garantir que as suas necessidades nutricionais sejam satisfeitas, sendo preciso que os alimentos complementares sejam oportunos, adequados, seguros e consumidos de forma apropriada (CARLETTI et al., 2017). Ademais, esse período é de elevado risco para a criança, dado o uso de alimentos desaconselháveis e também pelo risco de contaminação em razão da manipulação e preparo inadequado deles (SBP, 2012).

A alimentação correta no momento ideal é essencial para melhorar a sobrevivência infantil e promover o crescimento e o desenvolvimento saudáveis. Os primeiros dois anos da vida de uma criança são particularmente importantes, pois a nutrição ideal durante esse período reduz a morbimortalidade, diminuindo o risco de doença crônica e promovendo um melhor desenvolvimento geral (WHO, 2018b).

Embora se conheça os resultados prejudiciais de uma alimentação inadequada para o crescimento e desenvolvimento infantil, as práticas alimentares das crianças brasileiras ainda se encontram muito aquém das recomendações de uma alimentação adequada e saudável.

Erros na introdução alimentar infantil são comuns no Brasil, como mostra estudo transversal realizado com 60 crianças de 4 a 13 meses de idade, que analisou a introdução da alimentação complementar e a ingestão de alimentos industrializados, posto que $10 \%$ da população estudada havia iniciado a alimentação complementar aos 4 meses. Tais erros ocorrem porque muitas mães são leigas quanto aos alimentos propícios para a criança e o momento certo de iniciar a introdução alimentar, além de receberem orientações equivocadas por parte dos profissionais de saúde e de não terem acesso a outras fontes de informação (SOMBRA et al., 2017).

Pesquisa que identificou as práticas alimentares de crianças menores de 24 meses que frequentavam Unidades Básicas de Saúde (UBS) na cidade de Diadema-SP, mostrou que, dentre as crianças menores de 6 meses, a prevalência de aleitamento materno exclusivo foi de $41,1 \%$ e $30,4 \%$ de aleitamento complementado. Nas crianças entre 6 e 23 meses, a prevalência de aleitamento materno foi de $44,4 \%$. Ainda nessa faixa de idade, $98,7 \%$ das crianças apresentaram consumo alimentar inadequado, e 60,8\% consumiam suco ou refresco industrializado, $54,3 \%$ ingeriam mingau com leite ou leite com espessante, $54,2 \%$ usavam refrigerante e $45,2 \%$ receberam papa salgada antes dos 6 meses de idade (COELHO et al., 2015).

Os resultados encontrados nas pesquisas sobre o consumo alimentar de crianças brasileiras são preocupantes, evidenciando que a utilização de alimentos saudáveis não faz parte do consumo diário familiar, podendo refletir em anemia e obesidade, dentre outros problemas de saúde, impactando nas condições de saúde e nutrição das crianças no momento atual e na vida futura (BORTOLINI; GUBERT; SANTOS, 2012).

Diante desse cenário, o profissional de saúde, em especial o enfermeiro, tem papel importante na promoção de uma alimentação infantil saudável, orientando as mães e crianças sobre as técnicas adequadas de preparo, higiene e noções de consistência e quantidades ideais das refeições com diversificação alimentar que contemple as necessidades nutricionais para cada fase do desenvolvimento (BRASIL, 2015b), 
por meio das consultas de enfermagem, em programas à saúde individual ou de grupos específicos, respaldadas pela legislação brasileira (BRASIL, 1986; BRASIL 1987; COFEN, 2018).

Assim sendo, este estudo teve como objetivo analisar a prática assistencial do enfermeiro voltada ao incentivo e à promoção da alimentação saudável na consulta de enfermagem à criança menor de dois anos.

\section{MÉTODO}

Pesquisa descritiva exploratória, de abordagem qualitativa, realizada em quatro Unidades de Saúde da Família (USF) do município de Cuiabá-MT, selecionadas por sorteio e nas quais a consulta de enfermagem à criança era feita como atividade programática.

Os dados foram coletados entre janeiro e fevereiro de 2012, utilizando-se da observação participante durante as consultas de enfermagem à criança entre 6 e 24 meses, período da infância em que as consultas de puericultura são realizadas com intervalos menores e as crianças são mais vulneráveis e demandam maiores cuidados profissionais, além de ser recomendado o aleitamento materno, a introdução alimentar e a alimentação complementar.

A observação participante pode ser definida como um processo em que se mantém a presença do observador numa situação social, com a finalidade de realizar uma investigação científica. O observador interage face a face com os observados, colhendo dados a partir da participação em suas vidas, em seu cenário cultural. Assim, o observador é parte do contexto sob observação, ao mesmo tempo modificando e sendo modificado por este contexto (MINAYO, 2007).

A técnica foi realizada por três pesquisadoras, que ficavam dispostas no consultório de enfermagem em locais estratégicos que possibilitasse a observação do ambiente, do enfermeiro, da mãe/acompanhante e da criança. A cada observação feita os dados eram registrados em diários de campo, um para cada pesquisadora, o que proporcionou três perspectivas dos acontecimentos. Ainda, para auxiliar a observação participante, os diálogos foram captados por meio de gravação em áudio para apreender melhor os detalhes.

Para a observação foi utilizado um roteiro previamente testado, que continha os seguintes elementos: identificação (nome da USF; caracterização das crianças; data do início e término da consulta); características do consultório de enfermagem; descrição da consulta de enfermagem, sendo focado: o acolhimen- to/interação, comunicação estabelecida; a avaliação do crescimento e desenvolvimento; a anamnese e coleta de dados (histórico de enfermagem); as condutas/encaminhamentos; orientações/práticas educativas e o uso da caderneta de saúde da criança.

Os critérios de inclusão das unidades para a pesquisa foram: USF localizada na área urbana da capital Cuiabá-MT e que realizavam consulta de enfermagem como atividade programática. Os enfermeiros afastados do trabalho durante a coleta de dados foram excluídos da pesquisa. Foram incluídas as consultas de enfermagem com crianças de zero a dois anos de idade, cadastradas e em acompanhamento na unidade, sendo excluídos do estudo aquelas que não compareceram à consulta na data agendada, com duração média de 30 minutos.

Antes de entrar em campo propriamente dito, foi realizado contato prévio com a Secretaria Municipal de Saúde para a obtenção da autorização para a coleta dos dados. Após as aprovações da Secretaria de Saúde do Município e do Comitê de Ética em Pesquisa (CEP), foram feitas visitas às USFs selecionadas e contato com as enfermeiras responsáveis, expondo os objetivos da pesquisa e como seria efetuada a coleta dos dados. Posteriormente ao consentimento do enfermeiro, foi elaborado um cronograma da atividade conforme a organização programática das consultas de enfermagem às crianças da área adstrita. A cada finalização da consulta, as pesquisadoras retiravam-se para analisar os dados, com a ciência do enfermeiro.

As observações foram transcritas e analisadas, averiguando se os objetivos da pesquisa haviam sido atingidos ou não. Com nove consultas, obtivemos dados suficientes para responder aos objetivos, finalizando, dessa forma, o trabalho de campo. Os dados obtidos da observação registrados em diário de campo e as gravações, foram transcritas fidedignamente. Para análise dos dados utilizou-se a técnica da análise temática proposta por Bardin (2011), operacionalizada em cinco etapas: pré-análise; exploração do material ou codificação; tratamento dos resultados; inferência; e interpretação.

Os dados foram discutidos a partir da literatura produzida sobre o tema e das diretrizes da alimentação infantil do Ministério da Saúde do Brasil, e das recomendações sobre alimentação infantil de sociedades cientificas, como a Sociedade Brasileira de Pediatria (SBP, 2012, 2018) e a Sociedade de Pediatria de São Paulo (SBP-SP, 2012). 
Da análise final dos dados foi possível a construção da categoria temática Promoção de hábitos alimentares saudáveis na consulta de enfermagem à criança.

Este estudo foi aprovado por Comitê de Ética em Pesquisa, protocolo no 129/CEP-HUJM/2011, tendo obedecido aos preceitos éticos de pesquisa com seres humanos e solicitada a assinatura do Termo de Consentimento Livre e Esclarecido (TCLE) tanto pelo profissional enfermeiro quanto pelo acompanhante da criança em duas vias; uma ficou com o pesquisador e a outra com o participante.

\section{RESULTADOS E DISCUSSÃO}

\section{Promoção de Hábitos Alimentares Saudáveis na Consulta de Enfermagem à Criança}

Os diálogos recortados mostram que os enfermeiros investigam e orientam as mães sobre a alimentação das crianças atendidas na consulta:

Enfermeiro: [...] pega o prontuário, dá uma rápida lida e pergunta: Então como é que foi desde que você veio da última vez e você estava começando a dar a papinha?

Mãe: é eu dei primeiro a fruta, aí depois que ele fez seis meses eu fui dar a comida.

Enfermeiro: e aí você deu a fruta, deu a papinha de legumes com batata, com o caldinho de feijão; tem dado ainda?

Mãe: sim, eu dou.

Enfermeiro: dá quantas vezes a papa salgada?

Mãe: dá meio-dia e à tarde, lá para as cinco e pouco. Almoço e janta. [...] (DIÁRIO DE CAMPO, CONSULTA 2)

Enfermeira: [...] e ele está comendo de tudo?

Mãe: come tudo o que a gente dá!

Enfermeira: passou a dar o feijão ou continua dando só o caldo?

Mãe: até o caroço mesmo se der ele come.

Enfermeira: e a carne?

Mãe: também come carne, frango.

Enfermeira: e frutinha, tá conseguindo dar todo dia?

Mãe: Sim eu tô dando. Ele come maçã, banana, uva. [...]. (DIÁRIO DE CAMPO, CONSULTA 5)
Verifica-se nos diálogos apresentados que, apesar de os enfermeiros investigarem sobre a alimentação da criança, essa é pontual para alguns alimentos e não leva em consideração a rotina, os hábitos familiares, o momento oportuno da faixa etária e do tipo de alimento a ser oferecido. É preciso que o enfermeiro faça uma investigação mais aprofundada, utilizando-se de inquéritos alimentares, como o método de recordatório alimentar das últimas 24 horas, para verificar com maior detalhamento o que a criança consome durante um dia de alimentação, a frequência de sua alimentação na última semana e a forma de preparo e consistência dos alimentos.

Perguntar apenas se a criança aceita ou não determinados alimentos que são oferecidos à criança, não fornece informações suficientes e precisas e não assegura que eles foram consumidos em quantidade e em qualidade adequadas. Além disso, a investigação requer que o enfermeiro pergunte à mãe sobre os alimentos utilizados, higienização, consistência, forma de preparo e processamento, como foram oferecidos e qual foi a aceitação da criança. Dessa forma, o enfermeiro pode saber com maior precisão o que a criança consumiu ao longo do dia e da semana e se os alimentos ofertados foram suficientes para a sua adequada nutrição.

O contexto de como os alimentos são introduzidos aos bebês é crucial para o desenvolvimento de bons hábitos alimentares e nos benefícios à saúde da criança a longo prazo. No trecho do diário destacado a seguir, percebe-se que o enfermeiro reconhece essa necessidade, orientando os pais quanto à importância de dar exemplos de bons hábitos alimentares à criança.

Enfermeiro: [...] ele almoça junto com vocês? Almoçar juntos desenvolve o vínculo com a família e cria rotina para criança. Almoçar no mesmo horário, não comer vendo TV, nem você nem ele. Em casa, ele vai copiar o que vê vocês fazendo. Então se ele vê você comendo doces, bebida alcoólica, chupando bala ele vai querer também, porque as crianças são seres humanos e nós somos programados para imitar o que os outros fazem [...]. (DIÁRIO DE CAMPO, CONSULTA 4)

A aquisição de hábitos alimentares saudáveis também vai depender de como a família se alimenta em seu cotidiano e o que ela entende por alimentação saudável. É fundamental que na consulta o enfermeiro investigue os hábitos alimentares familiares, principalmente dos cuidadores da criança (pais, avós, madrinhas, tias, vizinhas) e, a partir daí, realize a educação em saúde, buscando alternativas, propondo 
mudanças de comportamento e responsabilização de todos os membros da família com relação à nutrição da criança (SBP, 2012; BRASIL, 2015b, 2012).

Em estudo realizado na Holanda com o objetivo de investigar os fatores associados à introdução precoce da alimentação complementar (ou seja, antes dos 4 meses) e os fatores associados ao consumo infantil de alimentos não recomendados, incluindo bebidas doces e salgadinhos, os pesquisadores encontraram que $21 \%$ das crianças estudadas tiveram a introdução alimentar realizada antes dos 4 meses de idade e $27 \%$ estavam ingerindo alimentos inadequados aos seis meses de idade. Dentre essas crianças que tiveram a introdução complementar realizada de forma equivocada, os pais relataram que elas preferiam e aceitavam melhor os alimentos quando os mesmos estavam consumindo (WANG et al., 2019).

Para a formação de bons hábitos alimentares na infância, o Departamento de Nutrologia da Sociedade Brasileira de Pediatria (SBP, 2012) recomenda o respeito ao ritmo de desenvolvimento de cada criança; que a alimentação complementar seja realizada junto com as refeições em família, incentivando a interação entre os membros da casa; que os pais sejam exemplo de hábitos alimentares saudáveis e respeitem os limites impostos pela baixa idade, sempre agindo como um facilitador no processo de alimentação; proporcionando um ambiente tranquilo sem a utilização de estratégias coercitivas ou punitivas (WEFFORT, 2017).

Outro aspecto que deve ser considerado pelo enfermeiro que assiste a criança é a diversidade cultural das famílias, respeitando e promovendo a identidade alimentar das diferentes regiões brasileiras por meio do resgate e da valorização dos alimentos regionais, como frutas, verduras e legumes (BRASIL, 2012). Durante as consultas não foi observada nenhuma preocupação ou conduta do enfermeiro nesse sentido.

$\mathrm{Na}$ introdução da alimentação complementar é comum a criança apresentar dificuldades em aceitar determinados alimentos que não lhe são familiares ou mesmo que, em uma primeira oferta, ela não se identifique com o gosto no paladar ou mesmo não aceite a consistência e a forma de preparo.

Enfermeira: [...] você se lembra que eu orientei você a oferecer suco de couve? E aí?

Mãe: suco ele não toma, fruta ele não come.

Enfermeira: Ih! Assim tá dificil V. (nome da criança).

Mãe: a única coisa que eu dou bastante para ele e que ele come é beterraba.

Enfermeira: e fruta, o quê que ele come?
Mãe: nada.

Enfermeira: nada de fruta.

Mãe: a única coisa que ele comeu foi uma pocã, mais nada.

Enfermeira: laranja, banana, maçã, uva, nada, nada?

Mãe: nada. Ele comia, daí de repente ele não quis mais comer; banana eu dava para ele e ele faz eca.

Enfermeira: e a vitamina de frutas $E$. (nome da mãe)?

Mãe: não.

Enfermeira: e salada de fruta?

Mãe: não tentei ainda... É eu posso tentar fazer isso.

Enfermeira: tem que mudar a textura dos alimentos, e saladinha?

Mãe: cenoura e beterraba dou para ele todos os dias.

Enfermeira: E as folhas verdes, agrião, rúcula?

Mãe: nada (balançando a cabeça negativamente) [...]. (DIÁRIO DE CAMPO, CONSULTA 8)

Nesta consulta, apesar de a enfermeira ter proposto alternativas para ingestão de frutas, poderia ter aproveitado a informação materna de que a criança gosta de beterraba e sugerido o suco de beterraba misturado com cenoura, laranja ou outra fruta que contenha vitamina $C$, sem adição de açúcar, em pouca quantidade, após a refeição, para auxiliar na absorção do ferro. Ou, ainda, propor sucos naturais de frutas que são adocicadas naturalmente, a exemplo da melancia, laranja, manga. Outro aspecto que poderia ter sido investigado nesta consulta é se a família ingere esses alimentos, uma vez que a aceitação da criança também está condicionada à alimentação dos demais membros e da percepção familiar de consumo dos alimentos. Ainda poderia averiguar o conhecimento da mãe sobre a importância de se ofertar tais alimentos à criança, orientando os benefícios deles, contribuindo para uma maior conscientização e estímulo da mãe para oferecê-los.

$O$ enfermeiro que atende a criança no período da introdução alimentar deve orientar os pais a exporem a ela os alimentos de forma variada e com frequência, para que haja o reconhecimento e aprendizagem por parte dela. Orientar também que nos primeiros dias é normal a criança derramar ou cuspir o alimento, o que não deve ser interpretado como rejei- 
ção (SBP, 2012). Em média, são necessárias de oito a dez exposições a um novo alimento para que ele seja aceito pela criança. Muitos pais, talvez por falta de orientação, não entendem que esse comportamento da criança é considerado normal e acabam interpretando a rejeição inicial do alimento como uma aversão permanente e desistem de oferecê-lo em outras ocasiões (BRASIL, 2015a).

As dificuldades enfrentadas pelas famílias para alimentarem seus filhos de forma saudável não estão relacionadas apenas a não aceitação do alimento por parte da criança, mas também à condição financeira desfavorável de não acessibilidade (BENTO; ESTEVES; FRANÇA, 2015; BUSATO et al., 2015), à falta de tempo em preparar as refeições, ausência de hábito em comer verduras e legumes, e não ter um horário fixo para realizar as refeições, comer fora de casa e ingerir alimentos gordurosos e enlatados, resultando em práticas alimentares inadequadas (BENTO; ESTEVES; FRANÇA, 2015).

O recorte do diário de campo a seguir evidencia a preocupação do enfermeiro com a condição econômica da família ao orientar a introdução de legumes e verduras na dieta da criança, recomendando que a mãe compre esses alimentos em uma horta localizada na comunidade com preços mais acessíveis:

Enfermeira: [..] Ela está precisando agora das foIhas verdes que contêm o ferro. E lá embaixo, lá tem uma horta que oh! Tão bonita aquela horta lá! Só folha bonita e barata! Que é o mais bonito, que é o melhor! [...]. (DIÁRIO DE CAMPO, CONSULTA 1)

A condição socioeconômica das famílias deve ser um aspecto a ser analisado pelo enfermeiro antes de orientar a alimentação da criança, pois a baixa renda pode dificultar o acesso a alimentos adequados na introdução alimentar, uma vez que as outras despesas familiares consomem grande parte de seus recursos (BENTO; ESTEVES; FRANÇA, 2015). Além disso, a baixa escolaridade materna (DALLAZEN et al., 2018; WANG et al., 2019), idade materna mais jovem (WANG et al., 2019) e a menor renda familiar estão associadas com a introdução de alimentos inadequados (DALLAZEN et al., 2018).

Nesse sentido, identificar os aspectos dificultadores, associados ao início precoce de determinados tipos de alimentos não recomendados na alimentação complementar, dentro do contexto de baixo nível socioeconômico, é de fundamental importância para auxiliar na criação de medidas com o intuito de viabilizar ações de saúde pública para a promoção e a incorpo- ração de práticas alimentares saudáveis ao longo da infância, com reflexos para a vida adulta (DALLAZEN et al., 2018).

Nessa perspectiva, o profissional de saúde deve procurar conhecer as propriedades e características das frutas, legumes e verduras regionais, bem como o período do ano em que são encontradas com menor custo nos mercados (BRASIL, 2015a) e orientar os familiares.

Os recortes do diário de campo a seguir trazem a abordagem do enfermeiro com relação à oferta de alimentos industrializados e guloseimas às crianças consultadas.

Enfermeiro: [...] e os doces, bolachas e iogurtes, tem dado também? (a irmã mais velha olha para o enfermeiro e ri da pergunta).

Mãe: ela gosta de tubaína.

Enfermeiro: ela gosta de tubaína? O açúcar muito cedo na vida faz a pessoa desenvolver maus hábitos alimentares, o açúcar e alimentos gordurosos. Se você não trouxer bala para ela, ela não vai querer, se ela não ver. A criança precisa comer alimentos naturais, coisas naturais, frutas, verduras para desenvolver bons hábitos alimentares, sem contar que você não vai gastar dinheiro com balas [...]

Enfermeiro: então, à medida do possível que você conseguir evitar dar doces, coisas industrializadas, você evita. Açúcar é uma delícia, mas faz um mal! [...]. (DIÁRIO DE CAMPO, CONSULTA 3)

Enfermeiro: [...] e você está dando Danone para ele, é isso que você falou? Danone? Alguma outra coisa? Bolacha? Alguma coisa industrializa$d a$ ?

Pai: ele come bolacha.

Enfermeiro: bolacha recheada? (pai responde afirmativamente com a cabeça). Então, bolacha recheada, Danone, essas coisas, a gente compra pronto e elas têm conservantes, excesso de sódio, que é o sal, tem açúcar demais. A gente precisava dar uma evitada nessas coisas. Essas coisas além de propiciarem problemas de saúde futuros, porque excesso de sal e de açúcar dá maus hábitos alimentares[...]. (DIÁRIO DE CAMPO, CONSULTA 4)

De modo geral, as guloseimas e os alimentos industrializados vêm sendo introduzidos muito precocemente na alimentação das crianças (BRASIL, 2015a; COELHO et al., 2015; BORTOLINI; GUBERT; SANTOS, 2012) em decorrência de não haver disponibilidade de tempo para prepará-los, por possuírem sabor agra- 
dável e terem aparência e cheiro bem atrativos para as crianças. Esses alimentos são ricos em gorduras, açúcar e sódio e não possuem o valor nutricional adequado para a alimentação infantil. Não é recomendável, portanto, que façam parte da rotina alimentar da família, especialmente da criança. Um alto consumo desses por período prolongado pode acarretar em maus hábitos alimentares e, consequentemente, desencadear distúrbios nutricionais como sobrepeso, obesidade e doenças carenciais (BRASIL, 2015b).

O enfermeiro deve levantar a frequência, o tipo e consumo de doces, guloseimas e alimentos industrializados e intervir adequadamente por meio da comunicação empática, compreensiva e dialógica, tal como foi observado na pesquisa, para que haja conscientização e desejo por mudança no comportamento familiar.

É preciso que o enfermeiro reforce, em suas consultas, que hábitos alimentares familiares podem interferir nas escolhas de consumo das crianças, como apontou estudo que avaliou a influência de hábitos familiares sobre o consumo de bebidas açucaradas em crianças brasileiras menores de dois anos, evidenciando que o consumo regular de bebidas açucaradas pelo adulto foi associado ao consumo pela criança, e a maior prevalência de ingestão de refrigerante pelas crianças foi encontrada em domicílios em que os adultos consumiam regularmente bebidas açucaradas (41,8\%) (JAIME; PRADO; MALTA, 2017).

$O$ enfermeiro, como transmissor de conhecimento, deve orientar as mães a evitarem alimentos ultraprocessados e industrializados, como biscoitos recheados, salgadinhos "de pacote", refrigerantes e macarrão "instantâneo", uma vez que são nutricionalmente desbalanceados e, em razão da sua formulação e apresentação, tendem a ser consumidos excessivamente e acabam substituindo os alimentos in natura (BRASIL, 2019). A introdução desses alimentos, em conjunto com o não aleitamento materno, prejudica o crescimento e o desenvolvimento da criança, além de favorecer a ocorrência de processos infecciosos, alergias e distúrbios nutricionais. Concomitantemente, substâncias presentes nesses alimentos podem irritar a mucosa gástrica da criança, comprometendo a digestão e a absorção de nutrientes, além de terem baixo teor nutricional (BRASIL, 2015a).

Foi observado durante uma consulta que a enfermeira detectou a necessidade de uma avaliação nutricional mais minuciosa e um acompanhamento multidisciplinar antes de indicar a alimentação complementar para a criança:
Enfermeira: Agora me diga o que você está dando de comida? Você falou que lá na creche dela tem uma nutricionista?

$$
\begin{aligned}
& \text { Mãe - Não sei. } \\
& \text { Enfó - Em qual creche ela está? } \\
& \text { Mãe - Creche A [...]. (DIÁRIO DE CAMPO, CON- } \\
& \text { SULTA 9) }
\end{aligned}
$$

Mesmo que a creche frequentada pela criança não tenha o profissional nutricionista, recai sobre a instituição a responsabilidade de prover pelo menos $30 \%$ das necessidades nutricionais das crianças, distribuídas em, no mínimo, duas refeições para as creches em período parcial e de não menos que $70 \%$ das necessidades nutricionais, distribuídas em, minimamente, três refeições para as creches em período integral (BRASIL, 2013).

Estudo que analisou o consumo alimentar de 86 crianças de 12 a 30 meses que frequentavam os Centros Municipais de Educação Infantil do município de Colombo, Paraná, identificou que $43 \%$ delas tinham elevada ingestão energética, alta ingestão de magnésio, vitamina A, cálcio e zinco, e os lipídeos, carboidratos, cálcio, ferro e fibras estavam abaixo dos valores recomendados (INOUE et al., 2015).

Por outro lado, em países desenvolvidos como a Holanda, a criança estar matriculada em uma creche é fator protetivo para a introdução precoce e incorreta de alimentos complementares. Este fator pode ser explicado pelas diferenças nos sistemas gerais de assistência à infância nos diferentes países, como política, questões sociais, dentre outros (WANG et al., 2019).

A promoção da alimentação saudável é fundamental para o adequado crescimento e desenvolvimento da criança em qualquer ambiente que ela frequente. Nesse sentido, o enfermeiro possui papel importante, posto que sua atuação na consulta de enfermagem está baseada em ações educativas e de orientação, que podem garantir o acesso e a promoção de uma alimentação saudável, estimulando bons hábitos alimentares, desaconselhando o consumo de alimentos não saudáveis e proporcionando mudanças de comportamento que auxiliam em escolhas conscientes. Para tal, deve valorizar, além dos aspectos biológicos, os socioeconômicos, culturais e emocionais que envolvem o processo de alimentação da criança e de sua família, conforme identificado por este e outros estudos (GÓES et al., 2018).

Pesquisas têm sido desenvolvidas com o intuito de compreender como os profissionais de saúde podem atuar de forma eficiente na abordagem da intro- 
dução alimentar saudável, porém desafios persistem e necessitam ser superados, a exemplo do estudo realizado no município de Viçosa, Zona da Mata do Estado de Minas Gerais, Brasil, que buscou investigar as fragilidades do processo de instalação de programas de promoção da alimentação saudável na infância, na perspectiva dos profissionais da Atenção Básica. Os resultados mostraram que em $36,71 \%$ das equipes não havia definição clara da periodicidade da avaliação nutricional, restringindo-se ao acompanhamento da criança apenas na puericultura, por meio da aferição antropométrica $(45,57 \%)$ ou associação de aferições antropométricas e orientações gerais sobre alimentação, cuidados e vacinação $(39,24 \%)$ (EINLOFT; COTTA; ARAÚJO, 2018).

Este resultados estes corroboram estudo realizado no Estado do Rio Grande do Sul, que observou que um dos temas menos abordado para promoção da saúde nas 816 equipes de saúde analisadas foi a alimentação saudável (KESSLER et al., 2018). Para sanar essas deficiências, uma sugestão é a oferta de capacitação aos profissionais que atuam na atenção primária por meio de oficinas, para que tenham embasamento científico a fim de garantir o sucesso no processo de promoção da alimentação saudável (FROIS; DOURADO; PINHO, 2016).

Uma limitação desta pesquisa foi a utilização pontual de algumas consultas de enfermagem à criança, uma vez que o acompanhamento de puericultura é contínuo, e o enfermeiro pode abordar aspectos que não foram observados especificamente na consulta avaliada. Os resultados, todavia, poderão despertar nos enfermeiros a necessidade de repensar suas práticas em relação à alimentação complementar, além de subsidiar a melhoria da qualidade da consulta de enfermagem à criança. Ademais, indicam a necessidade de investigações que analisem o cotidiano alimentar da criança em seu contexto de vida.

\section{CONCLUSÃO}

Os resultados do estudo reafirmaram a consulta de enfermagem como importante ferramenta para o incentivo e a promoção da alimentação saudável para a criança, em especial pelo seu caráter educativo e vínculo com a família.

Observou-se que os enfermeiros atuaram nos principais aspectos da alimentação complementar, abordando a importância dos bons hábitos alimentares na família, orientando as mães sobre a introdução dos alimentos e alertando que a restrição ou abuso de determinados grupos de alimentos podem trazer prejuízos à saúde da criança. Ações específicas, como orientações acerca das peculiaridades da alimentação infantil, higienização e da influência dos aspectos culturais, não foram contempladas, além da investigação mais aprofundada sobre a alimentação da criança, enfocando a preparação, a quantidade e a qualidade dos alimentos oferecidos.

Os resultados sinalizam para a necessidade de investimentos em capacitações e atualizações, especificamente da introdução alimentar saudável, para que os enfermeiros promovam o acompanhamento integral e de qualidade à criança.

Para a realização deste estudo não houve nenhuma fonte de financiamento parcial ou total e não há conflito de interesse.

\section{REFERÊNCIAS}

BARDIN, L. Análise de conteúdo. 6. ed. Lisboa: Edições 70, 2011.

BENTO, I. C.; ESTEVES, J. M. M.; FRANÇA, T. E. Alimentação saudável e dificuldades para torná-la uma realidade: percepções de pais/responsáveis por pré-escolares de uma creche em Belo Horizonte/MG, Brasil. Ciênc. Saúde Colet., v. 20, n. 8, p. 2.389-2.400, 2015.

BORTOLINI, G. A.; GUBERT, M. B.; SANTOS, L. M. P. Consumo alimentar entre crianças brasileiras com idade de 6 a 59 meses. Cad. Saúde Pública, Rio de Janeiro, v. 28, n. 9, p. 1.759-1.771, 2012. Disponível em: http://www.scielo.br/ pdf/csp/v28n9/v28n9a14.pdf. Acesso em: 4 jun. 2019.

BRASIL. Presidência da República. Casa Civil. Subchefia para Assuntos Jurídicos. Lei No 7.498, de 25 de junho de 1986. Dispõe sobre a regulamentação do exercício da enfermagem, e dá outras providências. 1986. Disponível em: http:// www.planalto.gov.br/ccivil_03/leis/L7498.htm. Acesso em: 2 jul. 2020.

BRASIL. Presidência da República. Casa Civil. Subchefia para Assuntos Jurídicos. Decreto № 94.406/87. Regulamenta a Lei no 7.498, de 25 de junho de 1986, que dispõe sobre o exercício da Enfermagem, e dá outras providências. 1987. Disponível em: http://www.cofen.gov.br/decreto-n-9440687_4173.html. Acesso em: 2 jul. 2020.

BRASIL. Ministério da Saúde. Secretaria de Atenção à Saúde. Departamento de Atenção Básica. Saúde da criança: crescimento e desenvolvimento. Brasília, DF: Ministério da Saúde. 2012. 272 p. Disponível em: http://bvsms.saude. gov.br/bvs/publicacoes/saude_crianca_crescimento_desenvolvimento.pdf. Acesso em: 11 mar. 2019.

BRASIL. Diário Oficial da União. Resolução no 26, de 17 de junho de 2013. Ministério da Educação Fundo Nacional de Desenvolvimento da Educação. Dispõe sobre o atendimento da alimentação escolar aos alunos da educação básica no âmbito do Programa Nacional de Alimentação Escolar. Disponível em: http://www.imprensanacional.gov. 
$\mathrm{br} /$ materia/-/asset_publisher/Kujrw0TZC2Mb/content/ id/30683767/do1-2013-06-18-resolucao-n-26-de-17-de-junho-de-2013-30683763. Acesso em: 11 mar. 2020.

BRASIL. Ministério da Saúde. Secretaria de Atenção à Saúde. Departamento de Atenção Básica. Dez passos para uma alimentação saudável: guia alimentar para crianças menores de dois anos: um guia para o profissional da saúde na atenção básica. 2. ed., 2. reimpr. Brasília: Ministério da Saúde. 2015a. 72 p. Disponível em: http://bvsms.saude.gov. br/bvs/publicacoes/guia_dez_passos_alimentacao_saudavel_2ed.pdf. Acesso em: 11 mar. 2020.

BRASIL. Ministério da Saúde. Secretaria de Atenção à Saúde. Departamento de Atenção Básica. Saúde da criança: aleitamento materno e alimentação complementar. 2. ed. Brasília: Ministério da Saúde. 2015b. 184 p. Disponível em: https://bvsms.saude.gov.br/bvs/publicacoes/saude_crianca_aleitamento_materno_cab23.pdf. Acesso em: 11 mar. $20 \overline{20}$.

BRASIL. Ministério da Saúde. Secretaria de Atenção Primária à Saúde. Departamento de Promoção da Saúde. Guia Alimentar para crianças brasileiras menores de 2 anos. Brasília: Ministério da Saúde, 2019. 265 p. Disponível em: http://189.28.128.100/dab/docs/portaldab/publicacoes/ guia_da_crianca_2019.pdf. Acesso em: 11 mar. 2020.

BUSATO, M. A. et al. Ambiente e alimentação saudável: percepções e práticas de estudantes universitários. Semina: $\mathrm{Ci}$ ências Biológicas e da Saúde, v. 36, n. 2, p. 75-84, jul./dez. 2015.

CARLETTI, C. et al. Introduction of complementary foods in a cohort of infants in northeast Italy: Do Parents Comply with WHO Recommendations? Nutrients [periódico na Internet], v. 9, n. 34, p. 1-11. 2017. Disponível em: https:// www.ncbi.nlm.nih.gov/pmc/articles/PMC5295078/pdf/nutrients-09-00034.pdf. Acesso em: 11 mar. 2020.

COELHO, L. C. et al. Sistema de vigilância alimentar e nutricional/Sisvan: conhecendo as práticas alimentares de crianças menores de 24 meses. Ciênc. Saúde. Colet., v. 20, n. 3, p. 727-738, 2015.

COFEN. Conselho Federal de Enfermagem. Resolução COFEN № 568/2018 - Alterada pela Resolução COFEN № 606/2019. Disponível em: http://www.cofen.gov.br/resolucao-cofen-no-0568-2018_60473.html. Acesso em: 2 jul. 2020.

DALLAZEN, C. et al. Introdução de alimentos não recomendados no primeiro ano de vida e fatores associados em crianças de baixo nível socioeconômico. Cad. Saúde Pública, v. 34, n. 2, p. 1-13, 2018. Disponível em: http://www.scielo.br/pdf/csp/v34n2/1678-4464-csp-34-02-e00202816.pdf. Acesso em: 11 mar. 2020.

EINLOFT, A. B. N.; COTTA, R. M. M.; ARAÚJO, R. M. A. Promoção da alimentação saudável na infância: fragilidades no contexto da Atenção Básica. Ciência \& Saúde Coletiva, v. 23, n. 1, p. 61-72, 2018.

FEBRASGO. Federação Brasileira das Associações de Ginecologia e Obstetrícia. Amamentação. Comissão Nacional Especializada em Aleitamento Materno, 2018. (Série orientações e recomendações Febrasgo, n. 6).
FROIS, S. F. B.; DOURADO, L. M.; PINHO L. Promoção da alimentação saudável entre profissionais de saúde na atenção primária. Rev. Bras. Promoç. Saúde, Fortaleza [periódico na Internet], v. 29, n. 4, p. 621-626, out./dez. 2016. Disponível em: https://periodicos.unifor.br/RBPS/article/view/5689/ pdf. Acesso em: 4 jun. 2019.

GÓES, F. G. B. et al. Nurses' contributions to good practices in child care: an integrative literature review. Rev. Bras. Enferm., v. 71, Suppl 6, p. 2.808-2.817, 2018.

INOUE, D. Y. et al. Consumo alimentar de crianças de 12 a 30 meses que frequentam Centros Municipais de Educação Infantil no município de Colombo, Sul do Brasil. Rev. Nutr. [periódico na Internet], v. 28, n. 5, p. 523-532, set./out. 2015. Disponível em: http://www.scielo.br/pdf/rn/v28n5/ 1415-5273-rn-28-05-00523.pdf. Acesso em: 4 jun. 2019.

JAIME, P. C.; PRADO, R. R.; MALTA, D. C. Influência familiar no consumo de bebidas açucaradas em crianças menores de dois anos. Rev. Saúde Pública, v. 51, Suppl 1, p. 1-13, 2017.

KESSLER, M. et al. Ações educativas e de promoção da saúde em equipes do Programa Nacional de Melhoria do Acesso e da Qualidade da Atenção Básica, Rio Grande do Sul, Brasil. Epidemiologia e Serviços de Saúde [periódico na Internet], v. 27, n. 2, p. 1-12, jun. 2018. Disponível em: https://doi.org/10.5123/S1679-49742018000200019. Acesso em: 4 jun. 2019.

MINAYO, M. C. S. O desafio do conhecimento: pesquisa qualitativa em saúde. 10. ed. São Paulo: Hucitec, 2007.

PLUYMEN, L. P. M. et al. Early introduction of complementary foods and childhood overweight in breastfed and formula-fed infants in the Netherlands: the PIAMA birth cohort study. European Journal of Nutrition, v. 57, p. 1.985-1.993, 2018. Disponível em: https://www.ncbi.nlm.nih.gov/pmc/ articles/PMC6060808/pdf/394_2018_Article_1639.pdf. Acesso em: 11 mar. 2020.

SBP. Sociedade Brasileira de Pediatria. Manual de orientação do Departamento de Nutrologia: alimentação do lactente ao adolescente, alimentação na escola, alimentação saudável e vínculo mãe-filho, alimentação saudável e prevenção de doenças, segurança alimentar. 3. ed. Rio de Janeiro, RJ: SBP; Departamento de Nutrologia, 2012. 148 p. Disponível em: https://www.sbp.com.br/fileadmin/user_ upload/pdfs/14. Acesso em: 11 mar. 2020.

SBP. Sociedade Brasileira de Pediatria. Manual de alimentação: orientações para alimentação do lactente ao adolescente, na escola, na gestante, na prevenção de doenças e segurança. 4. ed. São Paulo: SBP; Departamento de Nutrologia, 2018. 172 p. Disponível em: http://www.amape. com.br/wp-content/uploads/2018/12/MANUAL-NUTRO-SBP-2018.pdf. Acesso em: 11 mar. 2020.

SBP-SP. Sociedade de Pediatria de São Paulo. Departamento de Nutrição. Alimentação Complementar. Departamentos Científicos SPSP - gestão 2010-2013. Recomendações: Atualização de Condutas em Pediatria [periódico na Internet], v. 60, p. 7-14, fev. 2012. Disponível em: http://www. spsp.org.br/site/asp/recomendacoes/Rec_60_Nutricao.pdf. Acesso em: 4 jun. 2019. 
SOMBRA, P. V. et al. Alimentação complementar e ingestão de alimentos industrializados em crianças menores de três anos. Rev. Saúde e Desenvolv. Hum [periódico de internet], v. 5, n. 3, p. 45-51, out. 2017. Disponível em: https://revistas.unilasalle.edu.br/index.php/saude_desenvolvimento/ article/view/3957/pdf. Acesso em: 4 jun. 2019.

WANG, L. et al. Factors associated with early introduction of complementary feeding and consumption of non-recommended foods among Dutch infants: the BeeBOFT study. BMC Public Health, v. 19, n. 388, p. 1-12, 2019. Disponível em: https://bmcpublichealth.biomedcentral.com/track/ pdf/10.1186/s12889-019-6722-4. Acesso em: 11 mar. 2020.

WEFFORT, V. R. S. (org). A alimentação complementar e o Método BLW (Baby-Led Weaning). Guia prático de atualização Departamento Científico de Nutrologia. Sociedade Brasileira de Pediatria [periódico na Internet], n. 3, maio 2017. Disponível em: https://www.sbp.com.br/fileadmin/ user_upload/19491c-GP_-_AlimCompl_-_Metodo_BLW. pdf. Acesso em: 4 jun. 2019.

WHO. World Health Organization. Infant and young child feeding. Geneva: World Health Organization, 2009. Disponível em: https://apps.who.int/iris/bitstream/handle/10665/44117/9789241597494_eng.pdf?sequence=1. Acesso em: 11 mar. 2020.

WHO. World Health Organization. Guideline: counselling of women to improve breastfeeding practices. Geneva: World Health Organization. 2018a. Disponível em: https://apps.who.int/iris/bitstream/handle/10665/280133/ 9789241550468-eng.pdf?ua=1. Acesso em: 11 mar. 2020.

WHO. World Health Organization. Infant and young child feeding. 2018b. Disponível em: https://www.who.int/news-room/fact-sheets/detail/infant-and-young-child-feeding. Acesso em: 11 mar. 2020. 